\title{
Correlates of cervical cancer screening uptake among female under graduate students of Aksum University, College of Health Sciences, Tigray, Ethiopia
}

\author{
Dawit Gebregziabher ${ }^{1 *}$, Eskedar Berhanie ${ }^{1}$, Tsiyon Birhanu $^{1}$ and Kidanemariam Tesfamariam²
}

\begin{abstract}
Objectives: Cervical cancer is among the leading cancer related causes of morbidity and mortality of women in the world. Ethiopia is among the highest risk countries with age adjusted incidence of cervical cancer 35.9 per 100,000 women or 7619 new cases and 6081 deaths of cervical cancer each year. The aim of this study was to examine correlates of cervical cancer screening uptake among female under graduate students of Aksum University, College of Health Sciences. Data was collected using self-administered structured questionnaire. Variables that were statistically significantly associated with the outcome in bivariate analyses were considered in a logistic multivariate regression analysis.

Result: Only $17.2 \%$ of students were screened for cervical cancer in their lifetime. Both in bivariate and multivariate analysis, sexual experience (AOR $=38.85 ; 95 \% \mathrm{Cl}[8.907,169.51])$, marital status (AOR $=3.481 ; 95 \% \mathrm{Cl}[1.167,10.380])$, Ppace of birth (AOR $=3.359 ; 95 \% \mathrm{Cl}[1.559,7.235])$, and student's year of study (AOR $=0.005 ; 95 \% \mathrm{Cl}[0.001,0.031])$ were the only correlates of cervical cancer screening uptake among female students. Therefore, the overall cervical cancer screening uptake was low and further study should be done other correlates.
\end{abstract}

Keywords: Cervical cancer screening, Correlates, Uptake

\section{Introduction}

Cervical cancer $(\mathrm{CC})$ is a malignant tumor of the cervix affecting the outermost squamous or inner glandular cells [1]. It is the fourth most common cancer in women, worldwide [2]. Cervical cancer is highly linked to preventable sexually acquired infection with certain types of HPV (16 and 18) [3]. HPV infection has been shown as the primary agent of cervical cancer and it can be diagnosed through routine screening based on clinical history and/or physical findings and confirmed by cervical punch or cone biopsy [4].

Cervical cancer is common among women worldwide. Most cases that occur in developing countries are related

\footnotetext{
*Correspondence: dawit23natieku@gmail.com

${ }^{1}$ Nursing School, College of Health Sciences and Comprehensive Specialized Hospital, Axum University, Tigray, Ethiopia

Full list of author information is available at the end of the article
}

to the availability of screening and to human papillomavirus vaccination programs [5]. Screening can detect precursors and early-stage disease for both types of cervical cancer: squamous cell carcinoma and adenocarcinoma. Treatment of precursors and early-stage disease can prevent the development of invasive cervical cancer and reduce cervical cancer mortality [6]. Cervical cancer screening began with the development of the Papanicolaou (Pap) test. In countries that adopted Pap test screening, the incidence and mortality of cervical cancer have decreased. In addition to the Pap test, screening methods now include tests for high-risk strains of HPV, which are central to the pathogenesis of cervical cancer. Infection with high-risk strains of HPV and persistence of HPV infection are the most important correlates of progression to cervical cancer [7].

An estimated 70,722 new cervical cancer cases occur annually in sub-Saharan Africa, which was the highest in 
the world with age standardized incidence rate of 31 per 100,000 women and varies across the regions with 42.7 in east Africa and 29.3 in western [8]. Ethiopia is among the highest risk countries for cervical cancer and populations of 29.43 million women aged 15 and above are at greater risk to develop cervical cancer [9].

Cervical cancer screening is the process of detection of precancerous cervical lesions in healthy women before the lesions develop into cancer $[3,10]$. These precancerous lesions can be treated easily [11]. Cervical cancer screening tests are available globally and the screen and treat is one simplified approach that has been developed and accepted by WHO. It uses visual inspection with acetic acid (VIA) and immediate cryotherapy for secondary prevention of cervical cancer $[10,12]$. This approach has been adopted and is now being used in countries with limited resources such as Ethiopia.

According to $\mathrm{WHO}$, cervical cancer screening is aimed at all females in the target age group, followed by treatment of detected precancerous lesions so that the majority of cervical cancers are prevented. WHO further recommend that at least one cervical cancer screening be performed on any female who is 30 to 49 years old. However, this can be extended to females younger than 30 years provided there is evidence of a high [11].

The female University students of were chosen to participate in the study because they are mostly in the age group (18 to 30 years), which poses a greater risk of HPV infection. In addition, female students in the health field are responsible for primarily informing the individual on health issues and they also play a key role in raising awareness on the risks of cervical cancer [13]. Female students should especially be sensitive about female cancers such as cervical cancer, so that they can play a professional role in protecting and promoting community health as healthcare personnel. This study was aimed to examine correlates of cervical cancer screening uptake among female under graduate students of Aksum University, and to assist program planners and health educators to target and tailor prevention programs.

\section{Main text}

\section{Materials and methods}

An institutional based cross-sectional study was conducted among female under graduate students of Aksum University, College of Health Sciences from February to June 2018. Aksum University College of Health Science was established in May 2016. It was started giving service in 2016 and the hospital has 201 beds for admitted patients but there are 177 beds are currently provided service for patients. It is expected to serve 3.5 million people from 3 different zones of the Tigray region.
The source populations for this study were all female undergraduate students of Aksum University. All sampled female under graduate students were also studied population for this study. A multistage cluster sampling technique with help of random sampling was used to select a total of 344 female health sciences students of the Aksum University. All under graduate female students who were off campus during the study period were excluded from the study.

The student's cervical cancer screening practice for premalignant cervical lesion was measured their selfreport history of screening in the past 3 years. Students were asked ("Have you ever screened for cancer of the cervix?") Response options were binary: $1=$ Yes, $2=$ No. Further, they were also asked about the procedure used for screening, Response options according to the screening modalities examined in this study were $1=$ VIA, $2=$ Pap smear, $3=$ Biopsy $4=\mathrm{I}$ do not know?

Data was collected using standardized self-administered structured questionnaire. It was entered using Epi info version 7, cleaned and analyzed using Statistical package for social sciences version 22.0 software. Descriptive statistics was used to characterize the sample. The binary logistic regression model was employed to examine the statistical association between the outcome variable and selected independent variables. All variables with a $P$ value $<0.05$ were included in the multivariable analysis using default variable selection method. Ethical clearance was secured from institutional review board (IRB) of Aksum University, College of Health Science. Written consent was obtained from each participant. Information was recorded anonymously and confidentiality were assured throughout the study period.

\section{Result}

Socio-demographic characteristics of respondents of Aksum University

In this study, a total of 344 students completed the questionnaire making the response rate of $100 \%$. The mean $( \pm S D)$ age of students was $23.67 \pm 2.83$ years' ranging from 19 to 30 years. Two hundred sixty-one (75.9\%) of students came from urban and the rest 261 (75.9\%) were from rural setting. Regarding marital status, 28 (8.1\%) were married. Only 205 (59.6\%) had sexual experience, of those 132 (38.4\%) have had Multiple sexual partner. Regarding year of education, 55 (16.0\%) were first year students, $55(16.0 \%)$ second year, and $166(48.3 \%)$ were fourth year students and above. Two hundred forty-six (71.2\%) were Orthodox, 50 (14.5\%) protestants (Table 1 ). 
Table 1 Socio-demographic characteristic of female under graduate students of Aksum University, College of Health Science, Tigray, Ethiopia $(\mathrm{N}=344)$

\begin{tabular}{llc}
\hline Variables & Category & Frequency (\%) \\
\hline Age of respondent & $19-24$ & $249(72.4)$ \\
Marital status & $25-30$ & $83(24.1)$ \\
& Single & $254(73.8)$ \\
& Married & $28(8.1)$ \\
Sexual experience & In relationship & $62(18.0)$ \\
& Yes & $205(59.6)$ \\
Age at fist sex & No & $139(40.4)$ \\
Number of sexual partners & $15-20$ & $150(43.6)$ \\
& $>21$ & $56(16.3)$ \\
& None & $139(40.4)$ \\
Place of birth & Single & $73(21.2)$ \\
Level of education & Multiple & $132(38.4)$ \\
& Urban & $261(75.9)$ \\
& Rural & $83(24.1)$ \\
& Year I & $55(16.0)$ \\
& Year II & $55(16.0)$ \\
Religion & Year III & $68(19.8)$ \\
& Year IV and above & $166(48.3)$ \\
& Orthodox & $246(71.2)$ \\
& Catholic & $21(6.1)$ \\
& Muslim & $27(7.8)$ \\
& Protestant & $50(14.5)$ \\
\hline
\end{tabular}

\section{Knowledge about prevention, treatment and screening modalities of cervical cancer}

More than one-third 140 (40.7\%) students knew that cervical cancer could be prevented by avoiding multiple sexual partners, 56 (16.3\%) reported that HPV Vaccination prevent cancer of the cervix. Less than one-fourth 71 (20.6) of respondents do not know whether it is treatable or not, Of those, who responded that cervical cancer is treatable 98 (28.5\%) students said that cervical cancer can be treated by specific drug given by hospital.

Students were asked about the cost of treatment, 130 (37.8\%) answered it is free of charge, and 117 (34\%) did not know the cost of cervical cancer treatment. Regarding how frequent one should be screened for cervical cancer, $123(35.8 \%)$ students answered once a year and 105 (30.5\%) every 3 years. One hundred eighty-eight 188 $(54.7 \%)$ answered that women of above 25 years of age should be screened, while 91 (26.5\%) said that prostitutes should be screened (Table 2).

\section{Cervical cancer screening uptake}

Two hundred eighty-five $(82.8 \%)$ of participants were not screened for cervical cancer. Only $17.2 \%$ were screened in their lifetime. The most frequent reason for not screening was lack of decision to be screened 72 (20.9\%), 50 (14.5\%) said that it may be pain full, and 31 (9.0\%) said they feel shy.

\section{Correlates of cervical cancer screening uptake}

As can be noted from (Table 3), three of the seven variables which showed significant association with cervical cancer screening uptake in bivariate analysis could not persist as significant in the multivariable analysis. The results of multivariant analysis showed that after adjusting for number of sexual partners and age at first sex, only marital status, sexual experience, level of education and place of residency had showed overall significant association with cervical cancer screening uptake at 5\% level of significance (Table 3).

As a result, having previous sexual experience increases the odds of cervical cancer screening uptake by 38 times as compared to those who had never had sexual experience. $(\mathrm{AOR}=38.86,95 \% \mathrm{CI} 8.907,169.51)$. In addition, second year female students were $99.5 \%$ less likely to have been screened compared to fresh female undergraduate students (AOR $=0.005,95 \%$ CI 0.001, 0.031).

Married participants were 3.4 times more likely to be screened compared with Single participants $(\mathrm{AOR}=3.481,95 \%$ CI 1.167, 10.380). female students who had been born in urban area were also 3.3 times more likely to be screened compared to participants who were born in rural area $(\mathrm{AOR}=3.359,95 \% \mathrm{CI} 1.559$, 7.235).

\section{Discussion}

This study was aimed to examine correlates of cervical cancer screening uptake among female under graduate students in Aksum University. Of the 344 female students, only $59(17.2 \%)$ had cervical screening in their lifetime. This is higher than the study findings of MizanTepi (Ethiopia) 14.83\% ([14], 12.0\% in Ghana [15], 9.0\% from (Benin) [16], 0\% in India and 1.0\% Tunisia [17]. But it is lower than study conducted in 50.9\% (Barbados) [17], in Uganda (19\%) [18].The main reasons mentioned for not screened were lack of information, being healthy, shyness, did not decided to be screened, fear of vaginal examinations and pain.

In this study female students who have previous sexual experience had thirty-eight times higher odds of cervical cancer screening as compared to those without sexual experience $(\mathrm{AOR}=38.86,95 \%$ CI 8.907, 169.51). This finding is in line with a study conducted in 25 Low- and Middle-Income Countries (AOR $=3.62,95 \%$ CI 2.98, 4.39). But in contrary to what was found in Adama University (Ethiopia) $[17,19]$. The possible reason for these 
Table 2 Knowledge about prevention, treatment and screening modalities of cervical cancer of female under graduate students of Aksum University, College of Health Science, Aksum, Tigray, Ethiopia ( $N=344)$

\begin{tabular}{|c|c|c|}
\hline Knowledge variable & Category & Frequency (\%) \\
\hline \multirow[t]{5}{*}{ Prevention methods } & Avoiding multiple sexual partners prevent cervical & $140(40.7)$ \\
\hline & Avoiding early sexual intercourse & $88(25.6)$ \\
\hline & Quitting smoking prevent cervical cancer & $24(7.0)$ \\
\hline & Vaccination HPV prevent cervical cancer & $56(16.3)$ \\
\hline & Don't know & $36(10.5)$ \\
\hline \multirow[t]{2}{*}{ Know cancer of cervix can be treated } & Yes & $273(79.4)$ \\
\hline & No & $71(20.6)$ \\
\hline \multirow[t]{5}{*}{ Treatment type } & Herbal remedies & $44(12.8)$ \\
\hline & Specific drug given by hospital & $98(28.5)$ \\
\hline & Surgery & $126(36.6)$ \\
\hline & Radiotherapy & $62(18)$ \\
\hline & Don't know & $14(4.1)$ \\
\hline \multirow[t]{5}{*}{ How expensive do you think is treatment cervical cancer } & Free of charge & $130(37.8)$ \\
\hline & Reasonable price & $25(7.3)$ \\
\hline & Moderately expensive & $23(6.7)$ \\
\hline & Very expensive & $49(14.2)$ \\
\hline & Do not know & $117(34)$ \\
\hline \multirow[t]{3}{*}{ Frequency of screening } & Once a year & $123(35.8)$ \\
\hline & Every three year & $105(30.5)$ \\
\hline & Do not know & $116(33.7)$ \\
\hline \multirow[t]{3}{*}{ Who should be screened } & Women of $>25$ years & $188(54.7)$ \\
\hline & Prostitutes & $91(26.5)$ \\
\hline & Elderly women & $65(18.9)$ \\
\hline \multirow[t]{4}{*}{ Procedures used in cervical cancer screening } & VIA & $182(52.8)$ \\
\hline & Pap smear & $44(13.7)$ \\
\hline & Biopsy & $67(19.5)$ \\
\hline & Do not know & $48(14)$ \\
\hline
\end{tabular}

inconsistencies is difference in sample size and study population.

In addition, those Married participants were 3.4 times more likely to be screened compared with Single participants (AOR $=3.481,95 \%$ CI 1.167, 10.380). The findings of the present study are consistent with those of earlier study from 25 Low, Middle Income and Emerging Economy Countries (AOR $=3.20,95 \%$ CI 2.50, 4.09) [17].

This study also showed that female student's year of study was also significantly associated with the screening practice of respondents. It was observed that second year female students were $99.5 \%$ times less likely to have been screened $(\mathrm{AOR}=0.005,95 \% \mathrm{CI} 0.001,0.031)$. This is in agreement with a study conducted in Hawassa University $(\mathrm{AOR}=0.06,95 \% \mathrm{CI} 0.02,0.17)$ and Adama University $[19,20]$. This may be due to the influence of student's level of exposure to different medical courses which in turn affect their screening practice.

Students place of birth were also significantly with their screening practice. This study has revealed that, being born in urban area were also three times more likely to be screened than their rural counterpart $(\mathrm{AOR}=3.359,95 \%$ CI $1.559,7.235$ ). This is in line with a study conducted in Adama University [19]. This could possibly be due to differences in the population's exposure to technology, culture, and the participant's residence area.

\section{Conclusion}

In conclusion, this study revealed that female student's cervical cancer screening uptake was low and sexual experience, place of birth, students class level and marital status were the only correlates of cervical cancer screening uptake. Further study with large sample size should be done to examine other correlates.

\section{Limitation of the study}

Since our population interest were young female university students, and this has implications for the generalizability of the findings to less educated or older women. In addition, the cross-sectional nature of the 
Table 3 Bivariate and multivariable logistic regression analysis result of determinants of cervical cancer screening among female under graduate students of Aksum University, College of Health Science, Aksum, Tigray, Ethiopia ( $N=344)$

\begin{tabular}{|c|c|c|c|c|}
\hline \multirow[t]{2}{*}{ Variables } & \multicolumn{2}{|l|}{ Practice } & \multirow[t]{2}{*}{ COR $(95 \% \mathrm{Cl})$} & \multirow[t]{2}{*}{ AOR $(95 \% \mathrm{Cl})$} \\
\hline & Yes & No & & \\
\hline \multicolumn{5}{|c|}{ Age of respondent } \\
\hline $19-24$ & 49 (83.1.0\%) & $200(70.2 \%)$ & 1 & 1 \\
\hline $25-30$ & $10(16.9 \%)$ & 85 (29.8\%) & $2.968[1.707,5.159]^{*}$ & $0.989(0.337,2.902)$ \\
\hline \multicolumn{5}{|l|}{ Sexual experience } \\
\hline Yes & $45(76.3 \%)$ & $160(56.1 \%)$ & 1 & 1 \\
\hline No & $14(23.7 \%)$ & $125(43.9 \%)$ & $4.189[2.537,6.917]^{*}$ & $38.855[8.907,169.51]^{* *}$ \\
\hline \multicolumn{5}{|l|}{ Marital status } \\
\hline Single & $46(78.0 \%)$ & $208(73.0 \%)$ & & 1 \\
\hline Married & $6(10.2 \%)$ & $22(7.7 \%)$ & $2.669(1.046,1.808)^{*}$ & $3.481[1.167,10.380]^{* *}$ \\
\hline In relationship & $7(11.8 \%)$ & $55(19.3 \%)$ & $1.927(1.046,3.550)^{*}$ & $1.365(0.345,5.396)$ \\
\hline \multicolumn{5}{|l|}{ Place of birth } \\
\hline Urban & $43(72.9 \%)$ & $218(76.5 \%)$ & $3.672[2.194,6.144]^{*}$ & $3.359(1.559,7.235)^{* *}$ \\
\hline Rural & $16(27.1 \%)$ & $67(23.5 \%)$ & 1 & 1 \\
\hline \multicolumn{5}{|c|}{ Level of education } \\
\hline Year I & $12(20.3 \%)$ & $43(15.1 \%)$ & 1 & 1 \\
\hline Year II & $23(39.0 \%)$ & $32(11.2 \%)$ & $0.041[0.013,0.132]^{*}$ & $0.005[0.001,0.031]^{* *}$ \\
\hline Year III & $10(16.9 \%)$ & $58(20.4 \%)$ & $0.669[0.321,1.392]$ & $1.117[0.400,3.122]$ \\
\hline Year IV (above) & $14(23.7 \%)$ & $152(53.3 \%)$ & $2.393[1.210,4.732]^{*}$ & $1.463[0.763,5.274]$ \\
\hline
\end{tabular}

*P value $<0.05$ in bivarite analysis

**P value $<0.05$ in multivariable analysis

study means causal inferences cannot be made from the results reported. Yet another notable limitation were very wide confidence intervals for some of the covariates and lack of adjustment for lifestyle factors.

\section{Abbreviations}

AOR: adjusted odds ratios; CC: cervical cancer; Cl: confidence interval; COR: crude odds ratios; HPV: human papillomavirus; IQ: interquartile; Pap smear: papanicolaou smear; SD: standard deviation; WHO: World Health Organization.

\section{Acknowledgements}

Our deepest gratitude goes to Aksum University, Department of Nursing for their support. We would like to extend our sincere gratitude to the data collectors, supervisors and the study participants for being involved in the study.

\section{Authors' contributions}

DG conceived and designed the study, analyzed the data and wrote the manuscript. EB, TB and KT Data analysis, drafting of the manuscript and advising the whole research paper. EB were involved in the interpretation of the data and contributed to manuscript preparation. DG, EB involve in Tittle selection, Data analysis, drafting of the manuscript, approved the final manuscript. All authors read and approved the final manuscript.

\section{Funding}

There is no funding for this research. All cost of data collection and analysis were covered by the authors.

\section{Availability of data and materials}

All the necessary data and materials of this study are readily available in the supplementary material section of the journal of BMC in Research Note.
Ethics approval and consent to participate

Ethical clearance was received from Institutional Review Board (IRB) of Aksum University, College of Health Science and full written informed consent was obtained from participants. Privacy and strict confidentiality were maintained during the data collection process. No personal details were recorded or produced on any documentation related to the study. We declare that all necessary data's and materials are available in the manuscript and support information section of BMC in research note.

\section{Consent for publication}

Not applicable.

\section{Competing interests}

The authors declare that they have no competing interests.

\section{Author details}

${ }^{1}$ Nursing School, College of Health Sciences and Comprehensive Specialized Hospital, Axum University, Tigray, Ethiopia. ${ }^{2}$ Department of Medical Laboratory, College of Health Sciences and Comprehensive Specialized Hospital, Axum University, Tigray, Ethiopia.

Received: 18 July 2019 Accepted: 13 August 2019

Published online: 19 August 2019

References

1. Anderson KC, Alsina M, Bensinger W, et al. NCCN clinical practice guidelines in oncology: multiple myeloma. J Natl Compr Cancer Netw. 2009;7(9):908-42

2. Ferlay J, Soerjomataram I, Dikshit R, et al. Cancer incidence and mortality worldwide: sources, methods and major patterns in GLOBOCAN 2012. Int J Cancer. 2015;136(5):E359-86.

3. Parham GP, Mwanahamuntu MH, Hicks LM. A manual for physicians, nurse practitioners, and managers: custom publication of the African 
centre of excellence for women's cancer control. 2nd ed. Zambia: Lusaka; 2014. p. 42-44.

4. Anile M, Mantovani S, Pecoraro Y, et al. Pulmonary metastasectomy in uterine malignancies: outcome and prognostic factors. J Thorac Dis. 2017;9(Suppl 12):S1273-7.

5. Jemal A, Bray F, Center MM, et al. Global cancer statistics. CA Cancer J Clin. 2011;61:69.

6. Kjaer SK, van den Brule AJ, Paull G, et al. Type specific persistence of high risk human papillomavirus (HPV) as indicator of high grade cervical squamous intraepithelial lesions in young women: population based prospective follow up study. BMJ. 2002;325:572.

7. Committee on Practice Bulletins-Gynecology. Practice Bulletin No. 168: cervical cancer screening and prevention. Obstet Gynecol. 2016;128:e111

\section{(Reaffirmed 2018)}

8. Emmanuela G, Stella N, Zaid O. Coverage of cervical cancer screening in 57 countries: low average level and large inequalities. PLoS Med. 2008;5(6):e132.

9. Federal Democratic republic of Ethiopia Ministry of Health, Addis Ababa. 2015

10. Mwanahamuntu MH, Sahasrabuddhe WV, Blevins M, et al. Utilization of cervical cancer screening services and trends in screening positivity rates in a 'screen-and-treat' program integrated with HIV/AIDS care in Zambia. PLoS ONE. 2013;8(9):e74607.

11. Afri dev. Info. Africa Cervical Cancer Multi Indicator Incidence \& Mortality Scorecard. Information and analysis on health, population, human \& social development. 2014. (25/01/2016).

12. WHO. Guidelines for screening and treatment of precancerous lesions for cervical cancer prevention. WHO: Geneva; 2013.

13. Karadag G, Gungormus Z, Surucu R, Savas E, Bicer F. Awareness and practices regarding breast and cervical cancer among Turkish women in Gazientep. Asian Pac J Cancer Prev. 2014;15:1093-8.
14. Mulatu K, Motma A, Seid M, et al. Assessment of knowledge, attitude and practice on cervical cancer screening among female students of Mizan Tepi University, Ethiopia, 2016. Cancer Biol Ther Oncol. 2017;1:1.

15. Isara AR, Awunor NS, Erameh LM. Knowledge and practice of cervical cancer screening among female medical students of the University of Benin, Benin City Nigeria. Afr J Online (AJOL). 2013;1 (2).

16. Abotchie PN, Shokar NK. Cervical cancer screening among college students in Ghana: knowledge and health beliefs. Int J Gynecol Cancer. 2009:19:412-6

17. Pengpid S, Peltzer K. Attitudes and practice of cervical cancer screening among female university students from 25 low, middle income and emerging economy countries. Asian Pac J Cancer Prev. 2014;15:7235-9.

18. Klug SJ, Hetzer M, Blettner M. Screening for breast and cervical cancer in a large German city: participation, motivation and knowledge of risk factors. Eur J Public Health. 2005;15(1):70-7.

19. Tadesse A. Knowledge, attitude and practice towards screening for cervical cancer among Adama University female students. Ethiopia: Adama; 2014.

20. Tsegaye S, Mengistu D, et al. Knowledge and attitude towards cervical cancer screening and associated factors among female Hawassa university college of medicine and health sciences students. MOJ Public Health. 2018;7(3):151-8.

\section{Publisher's Note}

Springer Nature remains neutral with regard to jurisdictional claims in published maps and institutional affiliations.
Ready to submit your research? Choose BMC and benefit from:

- fast, convenient online submission

- thorough peer review by experienced researchers in your field

- rapid publication on acceptance

- support for research data, including large and complex data types

- gold Open Access which fosters wider collaboration and increased citations

- maximum visibility for your research: over $100 \mathrm{M}$ website views per year

At BMC, research is always in progress.

Learn more biomedcentral.com/submissions 